Banda, F. \& Kunkeyani, T. E. (2015). Renegotiating cultural practices as a result of HIV in the eastern region of Malawi. Culture, Health \& Sexuality: An International Journal for Research,

\title{
Renegotiating cultural practices as a result of HIV in the eastern region of Malawi
}

\author{
Felix Banda and Thokozani E. Kunkeyani
}

\begin{abstract}
A number of studies have shown that HIV awareness is very high among Malawians and yet infection rates are rising. Local cultural practices have been identified as contributing to this contradictory situation. Using data from 12 focus-group discussions collected in Balaka, Zomba, Machinga and Mangochi, the paper explores the reformulation of nine cultural practices as a preventive measure against HIV. The study reveals that cultural practices that involve sexual acts for completion are mediated through condoms and HIV tests. The study also shows that traditional herbs known for healing ailments are repurposed to symbolise sexual acts. We conclude that the idea of repurposing offers an avenue in which initiation and cleansing rites that involve sexual acts are replaced by other semiotics such as a traditional medicine called mtela. We also conclude that the modifications to cultural practices do not indicate complete abandonment of associated traditions, rather, they constitute the renegotiation of cultural practices and meanings associated with particular rites of passage. Lastly, we propose that a comprehensive prevention programme needs to be part of a wider national HIV-prevention effort combining a women and child rights and empowerment agenda and, critically, lifestyle lessons in a process of cultural renegotiation.
\end{abstract}

\section{Introduction}

The paper is motivated by the rising HIV epidemiological profile in Malawi and in the eastern region of the country in particular. This is happening despite the high number of local and international agencies involved in implementing initiatives for behaviour change communication. Although the data for this paper are drawn from the Eastern Region, which traditionally is seen as a Yao area, several other ethnic groups such as the Cewa, Lomwe and even the Tumbuka from the north have migrated to the area in search of job opportunities along Lake Malawi. The area also boasts major tourist attractions and cross-border trade with Mozambique and Tanzania. The region is therefore at the confluence of tourism, the transborder sex trade and the fish industry.

Considering this apparent diversity, we want to note from the outset that not all the practices discussed in this paper are performed by the Yao people. The discussion includes practices described by research participants associated with other ethnic groups, some of whom reside in the area. Where possible we shall indicate the ethnic groups associated with particular practices. In terms of information value, all the practices discussed in the 
paper are relevant to all ethnic groups in Malawi and Africa generally. The purpose of the paper is to explore the transformation of cultural practices that traditionally required sexual acts for completion, as preventive measure against HIV in the Eastern Region.

The focus is on how cultural beliefs on initiations and other traditional rites of passage are being renegotiated, while some cultural symbols are replaced or discarded as a result of the HIV pandemic.

The paper is divided into four sections. First, we contextualise the p roblem by reviewing the literature on cultural practices and rites of passage in Malawi. The focus is on cultural practices that traditionally use unprotected sexual acts for their completion. Second, we introduce the methodology and theoretical framework, focusing on the notion of semiotic remediation, which highlights acts of repurposing, that is, how certain practices and rites are mediated through taking up prior materials (already known cultural symbols and artefacts) at hand, putting them to present use and thus producing transformed circumstances for the activities and the community itself. Third, the paper shows how specific cultural practices and initiation rites have been remodelled to take into account the HIV pandemic.

\section{Socio-cultural contexts}

HIV awareness in Malawi is very high (DHS 2004; NAC 2005). Munlo (2011) contends that more than $90 \%$ of Malawians know how the virus is transmitted and how it can be prevented. Certain cultural practices have been blamed for the high prevalence rate. This is particularly the case because, as McCreary et al. (2007) contend, most Malawians (85\%) live in rural areas practicing traditional cultural practices, some of which run counter to the dictates of safe sex. Additionally, low school attendance among school-going children, and low literacy levels among Malawians generally, make it difficult to effectively disseminate HIV-prevention messages (Munthali, Chimbiri, and Zulu 2004). However, we want to note the rather narrow focus of the few studies that exist on the impact of HIV initiatives. Particularly, we want to note the dearth in studies assessing changes in sociocultural practices of Malawians, especially those in the Eastern Region, as a result of the HIV pandemic. There is a need for studies that explore the transformation and remediation of cultural practices and symbols in the face of the HIV pandemic.

As a way to contextualise the study further, below we review literature on cultural practices that have potential to spread HIV in Malawi.

\section{Cinamwali and jando initiation practice}

Cinamwali is a transitional rite that is practised in all parts of the country but may be known by different names. The ages of the initiates range from 6 to 13 years. Jando is the initiation rite for boys among the Yao in Mangochi and Machinga. The initiation for boys involves circumcision, that is, the cutting of the foreskin. In the past, it was only done by ngalibas or 'traditional male counsellors', who would use a small sharp knife for the circumcision of all the boys under one tsimba, 'initiation shelter'. These days, circumcision may sometimes be performed by medical personnel in a hospital and the initiated later transferred to a mosque or church to receive adulthood life lessons from religious leaders (MHRC 2005). 
In the past, after circumcision, the boys, now considered adults, went through another phase called kutaya mafuta, 'spilling/throwing away of body lotion', in which they were expected to complete the rite of passage by having sexual intercourse (MHRC 2005). The MHRC adds that this sexual act prevented boys from contracting tsempho (an illness whose symptoms were said to include continuous coughing and diarrhoea) that they may get 'once they start playing, or sharing food, with other children who, or whose parents had been having sex during the period the boys were at the thedzo [tsimba]' $(, 42)$. The belief is that if the boys do not have sex in this way, they will have later problems satisfying their partners sexually, and that girls will have difficult childbirths, become barren or become perpetually sick if they did not complete the rite through sexual acts.

Kunkeyani (2013) argues that while in the central region initiation takes place once when the girl has experienced her first menstruation, in the eastern region girls may have two initiations. The first is done between the ages of 6 and 13 years, before menstruation. This may involve having a boiled egg inserted into the vagina to break her virginity (Kunkeyani 2013). The first initiation is called msondo (MHRC 2005). This initiation does not take more than two weeks. The initiates are looked after by elderly women called anankungwi, or 'female initiators'. The second initiation takes place after menstruation and is called cindakula in Mangochi. According to the MHRC, the emphasis is 'for the girls to avoid having sex so that they do not get pregnant' (39). As Munthali, Chimbiri and Zulu (2004) and Munlo (2011) have argued, this message is contradictory because, as shown below, a fisi, or 'hyena', (a man designated to initiate girls into womanhood or cleanse a widow) may be deployed to have sex with the girls to initiate them into womanhood. Secondly, the girls are taught 'kunyekulira or kudikulira (to sexually wriggle the waist around) to assist men during intercourse' (MHRC 2005, 39). The songs that accompany the sex-simulating dances are replete with sexual innuendos and expletives. Thirdly, like the boys, girls are also encouraged into a sexual trialling practice called kudzola mafuta, 'to smear lotion on their bodies', or kusasa fumbi, 'removing dust from their bodies' (Kunkeyani 2013), a reference to the fact that they look 'dusty' as body lotion is prohibited while in the tsimba. Although the acts of cleansing are phrased euphemistically, they refer to sexual acts, as it is believed sexual intercourse 'dusts' the initiates clean. Kunkeyani (2013) notes that sometimes elderly senior men cleanse the girls and elderly senior women cleanse the boys.

\section{Fisi, 'the hyena,' ritual}

Fisi is the Cewa language name for hyena. It refers to a man whose role is to sexually initiate girls to complete the rites into womanhood. Kunkeyani (2013) identifies three different types of fisi. The first type is performed when a couple fails to have children. The childless couple or relatives identify someone to help impregnate the wife to help them have a child. The fisi performs his cultural role and has no claim on the child or children he fathers. The second type of fisi is when a girl who has reached puberty, that is, has experienced her first menstruation, has to engage in sex with a man to complete her initiation into womanhood. This ritual as noted above is known as kusasa fumbi, 'to remove dust', meant to cleanse and purify her after her first menstruation. In their review of studies on adolescent sexual practices in Malawi, Munthali, Chimbiri and Zulu (2004) lament that 'the fisi can sleep with several girls on the same night and without

\section{https://repository.uwc.ac.za/}


any protection, thereby increasing the vulnerability of girls to sexually transmitted infections ... and HIV' (13). The third type of fisi ritual happens after a death in a family. A fisi is arranged to cleanse the widow to mark the end of the mourning period. The ritual liberates the widow to remarry if she so wishes. According to the MHRC (2005), it also prevents the dead person from haunting the bereaved partner and the immediate family. It is important to note the cultural bias here as it is the bereaved woman that undergoes cleansing, while the man 'inherits' another wife through the cultural practices of kulowa kufa, 'death cleansing', and cimeta tsitsi, 'bonus wife [inheritance]', both discussed below.

Kamlongera (2007) chronicles a 34-year-old woman's experiences of the fisi whenshe was eleven and a half years old in Blantyre, southern Malawi. Kamlongera describes the fisi's actions as statutory rape and calls for eradication of the practice. In addition to the psycho-physiological damage done as the sexual acts are non-consensual, the practice is objectionable even if it involves adult women since it violates girls and women's human rights and dignity in the name of culture.

\section{Kutola nsomba, 'picking fish'}

Elsewhere in Africa, studies have been conducted on the nature, context and implications of transactional sexual relationships in fishing communities, for instance along Lake Victoria in Kisumu, Kenya (Kwena et al. 2012) and the Kafue River on the Zambian Kafue Flats (Merten and Haller 2007). Kwena et al. (2012) investigate the jaboya system in Kisumu, in which women traders safeguard access to the fish by entering into a sexual transaction with the fishermen.

Nagoli, Holvoet and Remme (2010) describe transactional sex practices in Mangochi District, in the southern-eastern part of Lake Malawi. They argue that transactional sexual practices are most evident between November and April at the height of the fish catching season. However, this is also a season of food shortage and, thus, trading in fish 'offers income-generating opportunities for poor and food-insecure households' (74). This period also sees brisk a tourist business, with restaurants and rest-houses experiencing a spike in customers. Thus, we have the tourism and the fish industries colluding to boost the sex trade in the area, thereby increasing chances of HIV transmission.

Njaya and Kachilonda (2008) carried out a value chain study for usipa (Engraulicypris sardella), 'small fish', in the south-eastern part of Lake Malawi. They concluded that limited supply of condoms, low capital for women, the mobility of fishermen and limited HIV awareness were among the factors that make the fishermen in this area susceptible. Kambewa, Nagoli and Hü sken $(2009,12)$ note that whereas this study focused on usipa, it also did not expressly look at factors of susceptibility for women on the value chain. Thus, they investigated the vulnerability points along the fish market chain and concluded that women were most susceptible to contract HIV at the initial point of buying fish from the fishermen, as this is the time they compete for fish with other women. The vulnerability increases with a low catch as this raises the possibility of competing women to be forced into transactional sex for the fish. In the study area, the practice of paying for fish with sex is known as kutola nsomba or 'picking fish'. 


\section{Cimeta tsitsi, 'deceased wife replacement'}

Cimeta tsitsi, or 'one who cuts the hair', is a reference to a situation in some African cultures where the end of the mourning period is announced by family members cutting their hair. In this case, the end of mourning is announced by a family offering another girl to replace the deceased wife. Often, a younger sister or niece is offered to a husband as cimeta tsitsi or 'replacement of the deceased wife'. Munlo (2011) says that this sometimes happens when the girl's parents fear being asked to reimburse the lobola 'bride-price' received for the dead wife. It may also happen that the parents of the deceased wife want to continue to have access to the wealth owned by the son-in-law, or when they want the relationship to continue because the son-in-law is mannerly and hardworking. Often, the cimeta tsitsi is younger than the children left behind by the deceased wife but they are obliged to call her 'mother'.

\section{Mitala, 'polygamy'}

Polygamy is a social practice that involves a man marrying more than one wife. There are a number of purposes associated with the practice. In traditional and rural Africa, wives and children help in tilling the land and providing for the family generally (Gauseet 2001). Parker (2001) suggests that the practice is also believed to curtail unfaithfulness in that a man has more than one wife to satisfy his sexual needs. However, MHRC (2005) point out that polygamy may accelerate the spread of HIV as, if one of the women or the man is infected, there is a chance that the whole family will be infected. The study area being predominantly Islamic, a religion that allows polygamy up to four wives, the practice was found to be common. In this case, religion was the reason for polygamy. However, there are certain cases that polygamy happens through the cokolo practice of 'inheritance of a widow', as described below.

\section{Cokolo, 'wife inheritance'}

In this practice, the wife of a husband who dies is 'inherited' by his brother, cousin or nephew. The MHRC (2005) found that 53\% of respondents across Malawi said that wife inheritance takes place in their community. In the same report, respondents among the Yao in Mangochi, the Cewa of the central region and Lomwe and Amang'anja in Mulanje indicated that wife inheritance no longer took place. Most of the younger generation in particular said they had never witnessed cokolo in their lifetime. However, the report concludes that 'the practice, although in general decline, was said to have been quite widespread in all the three districts covered by this study in the north' (22). Thus, it could not be established that the practice had completely died out.

\section{Kulowa kufa/kupita kufa, 'death cleansing'}

This practice exemplifies the third type of fisi. Kulowa kufa/kupita kufa involves the cleansing of a widow by a close relative of the deceased. For instance, when a husband has died, the widow has to undergo a cleansing ritual, which involves having sex with a surviving brother. If the deceased had no brother, then an uncle or any close male relative available does the cleansing. The performative sexual act between the fisi and the bereaved woman is thought to appease the dead man's spirit (Jere 2009). This is why the act is also called kugoneka mizimu, 'making the spirits go to sleep', (MHRC 2005). According to Loosli (2004), it is believed that the widow is contaminated after the burial of the husband and thus has to be cleansed before she can remarry. Kulowa kufa releases 
her from marriage bond so as to enable her remarry and, as a purification rite, it symbolises the end of the mourning period (Jere 2009). The cleansing does not often happen in the case of widower. This cultural bias against women has been highlighted and condemned by non-governmental organisations (NGOs) as a violation of their human rights and dignity (see Munthali, Chimbiri, and Zulu 2004).

\section{Early marriage}

The practice of early marriage is found in many guises in Malawi, such as kutsomphora/kusomphola, or 'abduction', ukwati wotulira, or 'marriage by default', kupimbila, or 'debt repayment' and cimeta tsitsi and shanzi/mbirigha, or 'bonus wife', (MHRC 2005). In the past, girls as young as 12 years were given into marriage by their parents, while many boys married by the age of 17 . Although practices such as kupimbila could apply to boys, it is the girls that are most often put up as security, which suggests discrimination against girls (MHRC 2005). As soon as the groom or his representative pays lobola, the girl starts living with the groom as a wife. In the past (and even in recent times), if the girl was in school, she was forced to stop. Munthali, Chimbiri and Zulu (2004), in their study of adolescent sexual and reproductive health in Malawi, highlight the high number of girls, compared to boys, dropping out of school, which they attribute to discriminatory cultural practices.

The practice of kutsomphora/kusomphola or 'abduction or elopement', is similar to the culture in South Africa called ukuthwala, or 'kidnapping for marriage', in which a man may abduct a girl and sell her or force her into marriage. In a recent case in the Western Cape Province, a man was found guilty of kidnapping, assault and statutory rape after abducting a 14-year-old girl and forcing her into marriage. He was sentenced to 22 years in prison. The Sonke Gender Justice Network (2014), an NGO championing HIV awareness, gender equality and human rights in applauding the judgement warned the criminal justice system not [to] allow human rights violations to be disguised as cultural practices, and urged all leaders, including traditional leaders to condemn such practices'.

It is evident from the literature reviewed above that these cultural practices and their roles in spreading HIV are being debated in the public domains. Clearly, some of the cultural practices border on criminality, while others illustrate gender based biases and the systematic abuse of children and women, and particularly the statutory rape of minors. However, the literature does not tell us much about agency, that is, what people are themselves doing to modify these cultural practices as a result of the HIV pandemic, and thus re-fashion cultural norms in the process.

\section{Methods}

\section{Methodology and theoretical framework}

The focus of this paper is on the modifications and the remodelling of particular cultural practices designed to prevent infections and the spread of HIV. As authors, we are mindful that cultural traditions are maintained and transmitted through norms and values symbolised in certain ideas and artefacts. These are the socio-cultural resources that carry specific cultural meanings in different contexts. Modification and additions to social semiotics entail a shift in the meaning-making processes surrounding the cultural practices 
involved (Iedema 2003, 2010). Our interest is in the modification and remodelling of those cultural practices that require sexual acts to be consummated. This entails an examination of cultural (meaning) change due to the re-ordering and shifting of social semiotics, or mobilising certain semiotics to do new things (Prior and Hengst 2010). This is where the notion of semiotic remediation comes in (Bolter and Grusin 1999). Central to the notion is repurposing (Bolter and Grusin 1999), which, according to Prior et al. (2006, 734), refers to the diverse ways that human and non-human semiotic performances, histories or images are represented and re-used across modes, media and chains of activity. The issue here relates to mediation and repurposing of cultural norms and practices to mitigate the spread of HIV. Therefore, the centrality of remediation stems from ways that activity is repurposed through taking up materials at hand, putting them to present use and thus producing transformed circumstances for prospective accomplishment (Prior and Hengst 2010). This notion will be useful in understanding, for example, transformation of the verbalised kutaya mafuta, 'throwing away the lotion', into the semiotics of sexual acts in the rites of passage for girls into womanhood. The notion also becomes critical in demonstrating how certain cultural practices, including sexual acts associated with rites of passage, have been interceded by condom use or replaced with traditional medicinal herbs (mtela).

Since the goal is to explore agency and the kinds of mediation and repurposing of cultural practices as preventative measures, the study relies mainly on qualitative data. The number of respondents that mention particular measures are not as important as what individuals are doing, or have heard others do, to mediate cultural practices with the potential to transmit HIV. These provide an indication of what people are doing individually or as a community to protect themselves and others from HIV. This paper focuses on the modifications and remodelling of cultural practices in the Eastern Region, especially in the rural and urban areas of Balaka, Machinga, Mangochi and Zomba. This is part of wider study that focused on the impact of different modes of communication for HIV awareness in Malawi. The aims of the research were explained to respondents and, for those who were literate, confidentiality and consent forms were signed. Those who were unable to read and write had their verbal consent audio recorded. Respondents were not asked questions relating to their own HIV status or that of people they knew.

A total of 126 questionnaires were administered as follows: 39 questionnaires for community members in the urban area, 58 in the rural communities and 29 for key informants (KIs), which comprised project consultants, District Commissioners, District AIDS Coordinators, Community-Based Organisation leaders, Programme Coordinators of NGOs, radio stations, television stations and voluntary councelling and testing centres. However, for ordinary people we had to rely on interviews and focus-group discussions (FGDs) as literacy levels, especially in the rural areas of Balaka, Machinga, Mangochi and Zomba, are very low. For KIs, the plan was to have 10 interviews, coupled with three FGDs per district. The questionnaires and interviews were designed to capture preferences of language and modes of communication of HIV messages; quality of interpretation and understanding of HIV messages and the role of culture in the HIV epidemic; and measures being used to change or modify these cultural practices to prevent infection. The data analysis that follows, however, is based on 12 FGDs. The focus is on the cultural practices that have been changed or modified or stopped as a result of the onset of HIV.

\section{https://repository.uwc.ac.za/}




\section{Findings}

It was clear from the FGDs that the cultural practices that have been reported to have potential to spread HIV have not been completely abandoned. Some are less frequent than before, while others have been modified and remodelled to reduce chances of HIV infection. In this section, we focus on nine cultural practices that were mentioned as having seen change and reformulation with the coming of the HIV pandemic. These are: initiation for boys, initiation for girls, polygamy, early marriage, the practice of fisi, death cleansing, wife inheritance, kutola nsomba and the sex-work profession generally.

\section{Early marriage for girls}

Participants said this practice is on the wane. This is in line with other studies that found that the practice was not as prevalent as it was in the past (Munthali, Chimbiri, and Zulu 2004; MHRC 2005). The respondents attributed this to advocacy from the government and specific NGOs. The NGOs mentioned consistently were World Vision, Girl Guide and the Youth Network Organization. Laws forbidding underage marriage are also becoming easier to implement as traditional chiefs and NGOs are getting involved in monitoring them. Another cultural modification, some respondents noted, was that some parents would only agree for their child to marry if the man agreed to send her to school first. This effectively meant the girl was only betrothed to the future husband and then sent to school until she reached marriageable age. Furthermore, some respondents mentioned that it is not uncommon for both the groom and the girl to undergo HIV testing before consumating the marriage.

\section{The remodelling of polygamy}

This practice was found to be common because of the influence of Islam in the religion. In some cases, the cultural practice has been refashioned to avoid the spread of HIV. Some respondents reported that nowadays, when a man wants to take another wife, the first wife or other wives insist that the new wife has to go for HIV testing. If the couple had not taken an HIV test, all of them, including the bride, had to undergo testing. This is to prevent the new bride from bringing HIV into the family or to prevent her from getting infected.

\section{Modification to the initiation of boys and girls}

Some respondents said that some parents send their children to hospitals to get circumcised and when they are discharged from the hospital, they then go to the initiation camp to get counselling, advice and techniques on life as an adult. However, there are some families that still perform the old practice of circumcising boys in the initiation camps. They believe that sending children to hospital for circumcision dilutes the culture. Some noted the fee charged by health facilities as being 'expensive', and that public facilities need 'advance bookings which is not part of our culture' and which has been known to make initiates miss the initiation period during the winter season. The cold in the winter season is believed to make the wounds heal faster than in the heat of the summer season (Kunkeyani 2013). That said, even where initiates are sent to initiation camps, the initiation performed at the camp has also been modified. As noted by one respondent: 'the ngalibas do not use one blade as done in the past. They now use a different razor blade for each initiate' (James, 28 years old, male, Mangochi). ${ }^{1}$ Furthermore, the modification of 
the circumcision practice also applies to the use of the razor blade. Formerly, a sharp small knife, passed on from one generation of ngalibas to another, was used for all initiates. The knife has been replaced by a different razor blade for each initiate. This finding is in line with other studies, which show that this cultural practice still takes place (Munthali, Chimbiri, and Zulu 2004; MHRC 2005). Whereas initiation for boys is non-existent, unstructured or extremely limited among the Cewa and other groups, among the Yao it is very common (MHRC 2005).

The substitution of a tsimba by a hospital, the replacement of ngalibas and anankungwis with medical surgeons, and the use of individualised razor blades rather than the communal sharp knife, represent the re-ordering and shifting of social semiotics in the meaning-making process (Iedema 2010). This entails the re-conxtexualisation and renegotiation of the cultural practices and the associated semiotic resources required for the successful performance of the initiation rituals. Further, some respondents said that instead of sexual acts, the cultural practice has been modified by repurposing traditional medicine (mtela). The initiation camp counsellors give the initiates mtela to complete the initiation process. The herbs are called mtela, a local name referring to herbs that are not harmful but helpful to people. The practice of kusasa fumbi or kucotsa fumbi for boys and girls is thus consummated not through sexual acts but through the initiates taking traditional medicine to protect themselves from tsempho. This is the belief 'that if the boys do not have sex, their penises would shrink and become too small for sex' and that the girls would suffer from kutuwa, 'getting pale' or be afflicted by bad omens or become barren (MHRC 2005, 42).

The use of condoms is another measure mentioned. Since one of the major lessons taught at initiation schools is avoidance of having children out of wedlock, NGOs and government agencies have been promoting the use of condoms for safe sex, even for the initiates. Evidently, this message of avoidance contradicts the cultural practice of kucotsa fumbi. This has also posed a dilemma to the churches and the mosques that have been involved in the initiation of boys and girls. The MHRC (2005) reports that for strict Christians and Muslims, their children may be circumcised at hospitals and thereafter initiates congregate at a church or mosque where respective religious leaders take the role of ngalibas to provide advice. Although religious leaders give life lessons to initiates, they preach abstinence from sex until marriage.

Some respondents were not amused with these changes to cultural practices. They particularly did not like modifications to the initiation for girls. They said this would lead to death of the community and the entire nation:

... yeah it's like to them cinamwali is something that they cannot part ways with, it is there for them .... (Jim, 25 years old, Mangochi FGD)

If it is changed, [do you want all of us will finish [i.e. die]? (Jerry, 25 years old, Mangochi FGD)

It was not only men, but also some female participants who wanted the initiation of girls to be done as was the case in the past, without any protection: 
We still do it. When boys come from initiation school, they are supposed to 'throw away' the body lotion or ointment. Because he is now a 'brother', how are we going to know that he is now 'our brother'? Even girls when they come from initiation, they are supposed to 'throw away' the body lotion without which then her friends will laugh at her ... ha..ha my friend these things are still practised... (Jane 27 year old female; Zomba FGD participant)

For this woman, and the rest of the members of the FGD, one cannot become a woman or man without performing the sexual act. It can be seen from the phrasing of the sentences and the nervous laughter of those against modification, that they are aware of the tsempo, which befalls dissenters to the initiation practices.

\section{The 'new' fisi carries a chishango (Shield)}

Respondents said that the practice of fisi has not died down completely but its execution has seen modification. In the first type of fisi in which a man helps out a couple that cannot have children, the men and women involved in a sexual encounter sometimes undergo HIV testing. We also learnt that it is not uncommon for the fisi whose role is to initiate girls or boys, to carry a chishango, or 'Shield', a brand name of a popular condom, which is now used to mean any condom. Similarly, the sexual act involved in the third type of fisi, kulowa kufa, 'death cleansing', may be mediated by a condom or both participants undergoing HIV testing. We elaborate on this below. We also learnt that in some communities the sexual act has been replaced by the widow being given traditional herbs.

\section{Sexual cleansing}

The MHRC (2005) notes that in some areas it is now believed that the negative forces resulting from the spirit of the deceased husband and the wife being 'unclean' after the burial of the husband are so strong that using a condom during the cleansing process would not work. This is where strong medicine (mtela) comes to replace both the sexual act and the condom. Thus, the use of traditional medicine for the completion of both initiation and the mourning period processes reveals the reformulation of cultural beliefs and associated cultural practices. The use of mtela instead of the sexual act has altered the meaning making process related to the cultural practices (Iedema 2010). Mtela has replaced sexual acts as the main ingredient in the kupita kufa sexual cleansing practice.

Consequently, because of the shift from the practice of having a sexual act without protection to the practice of having a sexual act with a condom or after HIV testing, or the replacement of a condom and sexual act with traditional herbs, the meaning making surrounding initiation and cleansing has also changed. Thus, other avenues for completing initiation rites, performing cleansing rituals and ending mourning periods have now become available.

\section{Wife inheritance}

The cultural practice of cokolo, associated with the Tumbuka and Ngoni, has also seen some modifications. We were told that sometimes before a widow is inherited by a surviving relative, both have to undergo HIV testing. If one of the parties is found to be HIV-positive, then the inheritance falls through. In some communities, the practice has 
been adapted in such a way that the widow is not remarried but is asked to stay in the compound and be looked after materially and financially by the surviving relatives. The new 'husband' would support her in the same way he supports his wife but would not have any sexual contact. Thus, this practice has been mediated as HIV testing has been added to the practice while sexual acts have been de-emphasised or removed completely.

\section{Picking fish}

This practice too has been modified as girls and women involved in the act have begun to insist on condom use and to negotiate the terms for sexual acts. That women are able to transact sexual matters with men, itself indicates a change in cultural practices. The renegotiation of the cultural practices and taboos involving sexual matters help to elevate the women's status, however brief, as they can choose to agree or disagree or put forward counter terms. While we are aware that it is women that are often abused in transactional sex-for-fish trade (Nagoli, Holvoet, and Remme 2010; Hü sken and Heck 2012), we also want to note the euphemism behind the phrase 'picking fish', which suggests women are not always passive recipients in the sex-for-fish trade. The sex trade becomes an opportunity for them to increase profit margins. The changing power relations between those that are offering sex and those willing to buy it are encapsulated in the recent coinage in the study area called ambele cile. Ambele cile is a Yao language term meaning 'payment first/money first'. It has been popularised by women plowing the sex trade in the study area, which as noted earlier is also a tourist hub. The problem as shown below is that some customers insist on puleni, 'plain' sex and pay less if a condom is used. The dilemma for the woman is that more pay means a bigger risk of HIV and STI infections.

\section{The transformation of sex work through ambele cile}

Merten and Haller (2007), Nagoli, Holvoet and Remme (2010) and Kwena et al. (2012) suggest that women's vulnerability to contracting HIV increases as they have diminished power of negotiation, and that transactional sex happens so quickly that they are unable to insist on use of protection. However, the practice of ambele cile gives the women the window to negotiate whether to use a condom or not. The 'pay me first' practice elevates and transforms sex work into a negotiated business practice between willing seller and willing buyer. People who indulge in sexual activities for economic gain need to protect their investment by insisting on using condoms, even if this means getting less money than if they do it puleni, 'plain', as shown in the extract below. The three women in the FGD from which the extract was obtained were sex workers, who insist on clients using a chishango or condom.

We tell them to use a condom. If they refuse ... . as for me ... I send them away. However, when they use a condom they give us little money because we have refused to have unprotected sex [they all laugh]. (Malia, 28 years old female. FGD Mangochi area).

Here, we can see agency in the response as she changes from generic 'we' to a personalised and more aggressive address, 'I', in 'I send them away'. This suggests a momentary and individualised power over men, but the speaker then switches back to a weaker collective 'we' to reveal the precarious situation women find themselves as they are paid less for trying to protect themselves from HIV infection. That aside, the response still 
illustrates that the sex trade has been re-modelled in three ways. First, women are to some extent able to negotiate the terms of the sexual transaction, second, the act itself has been modified through the use of a condom and, third, we see the changing power relations in which a woman can refuse to have sex if a man insists on unprotected sex. These changes in cultural practices are socially transformative as they constitute the restructuring of belief systems and the renegotiation of socio-cultural contexts surrounding sex and power relations between women and men. As Iedema (2010) observes, meaning making is by choice. Thus, the woman's choice of insisting on the use of a chishango, 'condom', has brought in a new meaning to the sexual act, whose performativity is no longer controlled by the man only or the desire for puleni 'skin-to-skin' sexual acts. Condom use has come to mediate sexual acts. Thus, it is not just the female and male power relations that are transformed - the sexual act is transformed from mere sex to 'safe' sex. Thus, with chishango, the sexual act has been adapted for HIV.

\section{Conclusion}

The paper has shown that people, women in particular, are slowly taking charge in the fight against HIV. The performativity of the sexual practices are either (re)mediated through use of condoms, using 'cleansing' herbs or those involved undergoing HIV testing. The cultural practices may still exist but with either modified semiotics (e.g. sex with a condom rather than puleni sex) or repurposing (Bolter and Grusin 1999) objects (e.g. medicinal herbs being used for cleansing purposes). Repurposing showcases the manner in which the rites of passage and cleansing draw upon the qualities of new semiotic resources (essentially repurposed 'old' semiotics), new contexts and mediums as older cultural practices adapt to new forms of consummation. This means there is more than one way of accomplishing the rites of passage for girls and boys, and to cleanse the widowed, other than use of sex alone. Thus, sexual intercourse is decentred as the only means for cleansing or completing the initiation rituals.

The paper has illustrated how nine cultural practices are being reformulated through modification and remodelling to prevent spreading of HIV. We have shown how cultural practices are often (re)mediated by modification (e.g. use of condoms), removing sexual acts and repurposing in which cultural symbols and artefacts (e.g. traditional herbs) are used to represent sexual acts. We want to conclude that the cultural practices still pose a threat of transmitting HIV, but these can be allayed by some measures illustrated in the paper. These modifications and remodelling should not be seen as defiance of cultural practices, rather they constitute renegotiation of cultural values and associated meanings and remediation of the semiotics that bring them into reality.

Lessons from this study are important given the high prevalence of HIV in Malawi. Since it is difficult to stop entrenched cultural practices, it is important to find ways in which they can be remodelled and modified without appearing to impose new and alien norms. This paper, using the idea of repurposing, gives us a glimpse into how to design culturally appropriate HIV-intervention programmes in the study area and Africa generally. On the other hand, it is clear that some cultural practices have no place in the modern world as they trample on others' human rights and dignity. Cultural practices such as kutsomphora/ kusomphola, fisi, cimeta tsitsi and others, which force young girls into sexual acts or early 
marriage, or older women into unsolicited sexual acts, should be made illegal. Perpetrators of these practices should face the law as in the South African case described above.

Lastly, although the vast majority of studies and NGOs have focused on behaviour change and abstinence, this paper suggests that in the study area the HIV pandemic is a function of a lethal cocktail of cultural practices, the transactional sex-for-fish trade, poverty and socio-economic conditions, and the migrant- and tourism-triggered sex trade. This means that a more comprehensive HIV-prevention programme needs to be part of a wider national HIV and AIDS effort combining the women and child rights and empowerment agenda and lifestyle lessons in cultural renegotiation. It also needs to highlight use of condoms and other HIV- preventative strategies as part of transactional sexual practices. Mindful that women are exploited in sex transactions, we nevertheless want to end by noting that the practice of ambele cile, or 'pay me first', provides us a glimpse of how women can take charge of their destiny and negotiate on equal terms with men.

\section{Acknowledgement}

We would like to thank the Office of the Deputy Vice Chancellor (Academic) at the University of the Western Cape for funding towards the authoring of this article.

\section{Note}

1. Note that pseudonyms are used to protect the identities of respondents. 


\section{References}

Bolter, J., and R. Grusin. 1999. Remediation: Understanding New Media. Cambridge: MIT.

DHS (Demographic Health Survey). 2004. Demographic Survey Report. Zomba: National Statistics Office.

Gauseet, Q. 2001. "AIDS and Cultural Practices in Africa: The Case of the Tonga (Zambia).” Journal of Social Science \& Medicine 52 (4): 509-518.

Hü sken, S. M. C., and K. Heck. 2012. "The 'Fish Trader $b$ ' Model: Reducing Female Fish Traders' Vulnerability to HIV.” African Journal of AIDS Research 11 (1): 17-26.

Iedema, R. 2003. "Multimodality, Resemiotization: Extending the Analysis of Discourse as Multi- Semiotic Practice.” Visual Communication 2 (1): 29-57.

Iedema, R. 2010. "Resemiotisation of a Policy Initiative: Promoting Open Discourse as 'Open Communication about Clinical Adverse Events'." In Exploring Semiotic Remediation as Discourse Practice, edited by P. A. Prior and J. A. Hengst, 139 155. New York: Palgrave.

Jere, M. N. 2009. "The Influence of Cultural Practices on the Spread of HIV and AIDS on Zambian People." PhD diss., University of Pretoria.

Kambewa, P., J. Nagoli, and S. M. C. Hü sken. 2009. Vulnerability of Female Fish Traders to HIV/AIDS Along the Fish Market Chain of the Southeastern Arm of Lake Malawi. Analysis Report. Regional Programme Fisheries and HIV/AIDS in Africa: Investing in Sustainable Solutions. The World Fish Center. Project Report 1979.

Kamlongera, A. 2007. "What becomes of 'Her'?: A Look at the Malawian Fisi Culture and its Effects on Young Girls." Agenda: Empowering Women for Gender Equity 21 (74): $81-87$. Kunkeyani, T. E. 2013. "Modes and Resemiotisation of HIV/AIDS Messages in Malawi." Unpublished Doctoral thesis, University of the Western Cape.

Kwena, Z., E. Bukusi, E. Omondi, M. Ng'ayo, and K. K. Holmes. 2012. "Transactional Sex in the Fishing Communities Along Lake Victoria, Kenya: A Catalyst for the Spread of HIV." African Journal of AIDS Research 11 (1): 9-15.

Loosli, B. C. 2004. "Traditional Practices and HIV Prevention in Sub-Saharan Africa." [Cited February 10 , 2014.]. http://www.gfmer.ch/GFMER_members/pdf/Traditional_HIV_Loosli.pdf MHRC

(Malawi Human Rights Commission). 2005. Cultural Policies for Development Unit. Cultural Practices and their Impact on the Enjoyment of Human Rights, Particularly in the Rights of Women and Children in Malawi. Research Report Lilongwe: MHRC.

McCreary, L. L., C. P. N. Kaponda, K. F. Norr, D. L. Jere, C. H. Chipeta, K. K. Davis, and E. Batista. 2007. "Rural Malawians' Perceptions of HIV Risk Behaviors and their Sociocultural Context." AIDS Care 20 (8): 946-957.

Merten, S., and T. Haller. 2007. "Culture, Changing Livelihoods, and HIV/AIDS Discourse: Reframing the Institutionalisation of Fish-For-Sex Exchange in the Zambian Kafue Flats." Culture, Health \& Sexuality: An International Journal for Research, Intervention and Care 9 (1): 69-83.

Munlo, J. 2011. "The Perception of Malawians Living in Gauteng, South Africa, on Contribution of Indigenous Malawian Tribes' Cultural Practices to HIV Infection in Malawi." Unpublished Masters dissertation, University of the Witwatersrand. 
Munthali, A. C., A. Chimbiri, and E. Zulu. 2004. Adolescent Sexual and Reproductive Health in Malawi: A Synthesis of Research Evidence. New York: The Alan Guttmacher Institute.

Nagoli, J., K. Holvoet, and M. Remme. 2010. "HIV and AIDS Vulnerability in Fishing Communities in Mangochi District, Malawi.” African Journal of AIDS Research 9 (1): $71-80$.

NAC (National AIDS Commission). 2005. Malawi HIV and AIDS National Action Framework 2005-2009. Lilongwe: NAC.

Njaya, F., and D. Kachilonda. 2008. Fish Value Chain Analysis and Vulnerability of Actors in the Marketing of Usipa: Case of Msaka and Msitiwere Beaches on Lake Malawi. Mangochi: FAO.

Parker, R. 2001. "Sexuality, Culture, and Power in HIV/AIDS Research." Annual Review of Anthropology 30 (1): 163-179.

Prior, P. A., and J. A. Hengst. 2010. "Introduction: Exploring Semiotic Remediation.” In Exploring Semiotic Remediation as Discourse Practice, edited by P. A. Prior and J. A. Hengst, 1-23. New York: Palgrave.

Prior, P. A., J. A. Hengst, K. Roozen, and J. Shipka. 2006. “'I'll be the Sun': From Reported Speech to Semiotic Remediation Practices." Text Talk - An Interdisciplinary Journal of Language, Discourse Communication Studies 26 (6): 733-766.

Sonke Gender Justice Network. 2014. "On Ukuthwala as a Criminal and Serious Human Rights Violation.” Press Release, February 14, 2014. http://www.genderjustice.org.za 


\section{Ré sumé}

Plusieurs é tudes ont montré que le niveau de connaissances sur le VIH est é levé parmi les habitants du Malawi. Pourtant les taux d'infection augmentent dans le pays. Il a é té dé montré que les pratiques culturelles locales contribuent à cette situation contradictoire. En utilisant les donné es issues de 12 groupes de discussion thé matique conduits à Balaka, à Zomba, à Machinga et à Mangochi, cet article explore la reformulation de neuf pratiques culturelles en mesure de prévention du VIH. L'étude révèle que les pratiques culturelles qui comprennent des actes sexuels pour pouvoir ê tre ré alisé es font l'objet d'une mé diation par l'entremise de pré servatifs et de tests de dé pistage du VIH. L'é tude montre aussi que les mé dicaments traditionnels à base de plantes, connus pour soigner certains maux, sont reconvertis pour symboliser les actes sexuels. Nous concluons que l'idé e de reconversion offre un moyen selon lequel les rites d'initiation et de purification qui impliquent des actes sexuels sont remplacés par d'autres sémiotiques comme la médecine traditionnelle appelée mtela. Nous concluons é galement que les modifications des pratiques culturelles ne signifient pas un abandon total des traditions qui leur sont associé es. Elles constituent plutôt la rené gociation des pratiques et des significations culturelles associé es à des rites de passage particuliers. Enfin, nous proposons qu'un programme de prévention complet soit inté gré à une campagne nationale de prévention du VIH au sens le plus large, prenant en compte les droits et l'autonomisation des enfants et des femmes et, élé ment crucial, les expé riences de style de vie dans un processus de rené gociation culturelle.

\section{Resumen}

Varios estudios han mostrado que en Malaui, la conciencia sobre el VIH es alta y, sin embargo, las tasas de infecció n siguen en aumento. Igualmente, las prá cticas culturales locales han sido señ aladas como un factor que abona a esta situación contradictoria. Aprovechando la información surgida de los diálogos sostenidos al interior de doce grupos de reflexión en Balaka, Zomba, Machinga y Mangochi, el presente estudio examina la reformulació $\mathrm{n}$ de nueve prá cticas culturas como una medida tendiente a reducir la incidencia del VIH. Asimismo, establece que el uso del condó n y las pruebas de VIH son parte de aquellas prá cticas culturales que requieren de actos sexuales para llevarlas a té rmino. El estudio revela, ademá s, que las tradicionales hierbas medicinales se readaptan para simbolizar los actos sexuales. Los autores concluyen que la idea de la readaptació $n$ es una forma en que los ritos de iniciació $\mathrm{n}$ y de purificació $\mathrm{n}$, en los que intervienen los actos sexuales, pueden ser remplazados por otra semió tica, por ejemplo, la medicina tradicional llamada mtela. Asimismo, concluyen que las modificaciones a las prá cticas culturales no significan un abandono total de las tradiciones asociadas; al contrario, constituyen una renegociación de las prá cticas y los significados culturales asociados con particulares ritos de transició n. Para finalizar, los autores sostienen que un programa de prevención completo debe ser parte de un programa nacional de prevenció $\mathrm{n}$ del VIH má s amplio que abarque los derechos de las mujeres y de los niñ os, así como su empoderamiento, y, de mayor importancia, que aborde lecciones sobre estilos de vida en un proceso de adaptació n de prá cticas culturales. 